\title{
Barriers and Supports in Engineering Career Development: An Exploration of First-Year Students
}

\author{
Rosmery Ramos-Sandoval*, Jano Ramos-Diaz \\ Centre for Interdisciplinary Science and Society Studies, CIICS, Universidad de Ciencias y Humanidades, Lima, Lima-39, Peru
}

\begin{tabular}{l} 
A R T I C L E I N F O \\
\hline Article history: \\
Received: 31 August, 2020 \\
Accepted: 18 November, 2020 \\
Online: 08 December, 2020 \\
\hline Keywords: \\
Social Cognitive Career Theory \\
Barriers \\
Supports \\
Engineering student retention \\
\hline
\end{tabular}

\begin{abstract}
A B S T R A C T
Previous research has found that first-years in college is challenging due to changes in academic demands and the adaptation process. In addition to this, research on career development has found that barriers and supports may influence career interest, motivation to continue and student retention. This study explores the influence of specific supports and barriers among first-year engineering college students. To reach this goal, a case study was conducted with 425 engineering students at three universities in Lima, Peru. Based on Social Cognitive Career Theory (SCCT), we performed a Structural Equation Model (SEM) to assess effects of contextual factors such as barriers and supports on self-efficacy, coping self-efficacy, and goals. Results showed that certain supports and barriers influence selfefficacy, cope self-efficacy and goals. Effects of these factors in first-year students and possible strategies for retention in STEM careers are discussed.
\end{abstract}

\section{Introduction}

Science and technology are critical subjects for the advancement in societies because they create prosperity, wellbeing and more opportunities $[1,2]$. Despite its increasing importance in daily life, the necessary number of science, technology, engineering and mathematics (STEM) workers is not being produced [3]. As a result, this gap has become a major problem, especially in developing countries, given the pressure to become competitiveness in the global economy. Therefore, increase and retention of STEM students, graduates, and workers have vital importance for Latin-American organizations, governments and educational institutions.

Accordingly, Peru showed an increase in higher education enrollments, however, this tend to vary significantly in specific careers. A recent report showed that between 2008 and 2019, 771 900 and 1'509 400 students were registered at national level [4]. Although, the same report showed that in 2017 , more than a half $(52 \%)$ were in social sciences and only $27.8 \%$ were in engineering and technology. Nonetheless, the rates of registered students in STEM fields indicated that there was a decline between 2018 and 2019 [4]. Besides, previous official reports indicated that economic issues (31\%), job responsibilities (28\%), and family issues (14\%) [5] were the main reasons to suspend higher education in STEM. Based on the above-mentioned reports, it seems that several factors are involved in Peruvian STEM students'

"Corresponding Author: Rosmery Ramos-Sandoval, Email: rramos@uch.edu.pe choice to stay or leave university. In addition to this, these rates and factors may contribute to the gap in STEM careers in Peru. As a result, this may have economic and social consequences for the country development.

Therefore, exploring how environmental and behavioral process interact in engineering career behavior may help to understand the STEM gap and first-year Peruvian students experiences in STEM careers. What is more, research on these factors is scarce in Peruvian STEM careers. Therefore, by using a survey design, the present study aims to explore how specific barriers and supports may influence self-efficacy, cope selfefficacy and goals.

\subsection{Who leaves and who stays?}

First-years in higher education are critical for students due to changes in study style and the time that it takes to adapt from high school to college. Previous research suggested that it is critical to focus on factors related to students retention in early years of STEM careers [6-9]. This advice is particularly relevant especially in certain areas of Peru where a lack of knowledge from parents about higher education constitute an additional challenge for students. Moreover, lack of support in first-year students may generate a biased perception of higher education that may result in withdrawal. Therefore, it is crucial to get insights based on theory and evidence to understand first-year engineering career development in the Peruvian context. 
Consequently, the literature on engineering career behaviors has highlighted several factors involved in career progression. Previous studies identified that lack of enjoyment, interest in engineering courses, demotivation and unpreparedness were the main reasons to leave engineering careers $[8,10]$. In addition to this, Snyder and colleagues [7] found that self-perception, beliefs and motivations may influence competence and expectations for achievement in engineering career. Based on this, psychological factors seems to have effects in how students behave and take decisions as well as their drive to continue engineering careers.

\subsection{Self-efficacy, coping self-efficacy and goals}

One particular theory that has been useful in the explanation of career development is Social Cognitive Career Theory (SCCT) [11]. SCCT model hypothesizes the association between selfefficacy, outcome expectation, interest, goals, barriers and supports $[11,12]$. SCCT proposed that when someone feels competent concerning a specific activity (self-efficacy), they will anticipate positive results (outcome expectation) and will develop interest in that particular domain. As a result, subjects will set goals that later will become in actions, however, these will be affected by barriers and supports. However, this study will focus in how specific barriers and supports affect certain variables of the model. For instance, several models have been constructed in order to explore in more detail specific SCCT variables [13, 14].

The term self-efficacy is defined as beliefs that people has regarding their capabilities to achieve successfully a specific task $[15,16]$ whereas goals is defined as student's intentions to persist in their career. The term cope self-efficacy is defined as beliefs about one's ability to manage environmental obstacles in a particular domain [12]. In this regard, previous reports have found that specific contextual factors may influence student's selfefficacy, career goals and cope self-efficacy $[6,17,18]$. In addition to this, relationships between barriers and supports may be indirectly related through coping self-efficacy [19]. Similarly, recent reports indicated that goals may affect determination to engage in career behaviors and that it is mediated by barriers and supports $[11,17,20]$. Taken together, these studies support the notion that certain individual variables of SCCT are suitable to understand career progress. Therefore, using certain core variables from SCCT seems suitable to understand in more detail how specific barriers and supports (e.g. Economics, Institutional and Family) interact with self-efficacy, cope self-efficacy and goals.

\subsection{Barriers}

Much of the current literature on contextual factors in career development pays particular attention to barriers and supports. Barriers refer to negative contextual influences that hinder different aspects of career progress $[12,21]$. In addition to this, previous research identified that barriers are associated with career-related behaviors, engineering college student's progress and attrition [22-24]. Moreover, recent studies found that barriers associated with family, social networks and lack of social support may influence career choice and decision to stay or leave current careers $[25,26]$. These studies suggest that there is an interaction between internal and contextual factors that may affect student's decision to continue engineering degrees and possible consequences such as withdrawal. Besides, specific differences in culture and context may change how these barriers are expressed in the Peruvian context. Therefore, exploring in more detail how these barriers interact could provide useful insights into Peruvian universities and possible interventions to reduce possible dropouts in engineering college students.

\subsection{Support}

On the other hand, support is defined as an environmental variable that facilitates the formation and pursuit of an individual's career choice [12]. Previous research has established that parents or family support have a critical role on vocational behavior and educational outcomes in undergraduate students [22]. In addition to this, peer social support was also positively associated with higher levels of aspiration and expectation in high school students [27]. Furthermore, Lent et al. [28] proposed that certain supports such as teaching staff or family are relevant in career decisionmaking and expectancies of career success. Therefore, by identifying specific supports, we could explore to what degree these may affect students career behavior (e.g. self-efficacy, coping self-efficacy and goals). In addition to this, by exploring these factors, Peruvian educational institutions may minimize the pre-existent barriers that exist in state engineering faculties such as the lack of resources, materials, equipment and quality standards. Moreover, it may contribute to develop strategies for education as a whole and increase student's retention.

Therefore, the present study aimed to explore the relationship between self-efficacy, cope self-efficacy and goals and how they interact with specific barriers and supports. Based on previous research [21-23, 29], the following hypotheses are proposed:

- H1. Social acceptance support have a direct effect on selfefficacy, goals, and cope self-efficacy.

- H2. Family support have a direct effect in self-efficacy, goals, and cope self-efficacy

- H3. Economic support have a direct effect on self-efficacy, goals, and cope self-efficacy.

- H4. Teacher support has a direct effect on self-efficacy, goals, and coping self-efficacy.

- H5. Social barriers have negative effects on engineering student's self-efficacy, goals, and their cope self-efficacy.

- H6. Economic barriers have negative effects on self-efficacy, goals, and cope self-efficacy.

- H7. Gender barriers have negative effects on self-efficacy, goals, and cope self-efficacy.

- H8. Teacher barriers have negative effects on self-efficacy, goal, and cope self-efficacy.

- H9. Racial barriers in have negative effects on self-efficacy, goal, and cope self-efficacy.

\section{Methodology}

\subsection{Data collection}

This research was carried out by contrasting the reference sample universe $(\mathrm{N}=40962$; Male $=77 \%$; Female $=23 \%)$ in students population enrolled at three university campuses in the North of Lima, Peru. This information was obtained from government public information [30]. To calculate the sample size, we used the finite population analysis formula which is considered to have a $95 \%$ confidence level. The final sample was composed of 425 engineering students $(77.4 \%$ males; $22.6 \%$ females) from ten engineering fields. The mean age of participants was 21 years 
$(\mathrm{SD}=4.02 ; \mathrm{Min}=16 ; \mathrm{Max}=38)$. As mentioned before, female students in this sample were low $(<23 \%)$ and this was aligned with national reports for female engineering students $(25 \%)$ [30]. Before data collection, ethical standards were considered such as the right to withdrawal, inform consent and anonymity protection.

\subsection{Survey characteristics}

The Spanish version from the Engineering Field Questionnaire [31] was used from the original version of Social Cognitive Career Theory proposed by Lent, Brown \& Hackett [11,12]. This study employed the following SCCT core variables to model the multiple relationships in the hypotheses mentioned before.

The first construct was designed to test participant's selfefficacy. This scale had 4-items with a 9-point Likert scale that ranges from 0 (no confidence at all) to 9 (complete confidence). Example items included: "How confident are you about performing well in your training over the next two courses?" To find out participants goals, 4 items were used to measure student's intention to persist. Each item was scored on a 5-point Likert scale (strongly disagree, disagree undecided, agree, strongly agree). An example item included: "I expect to remain enrolled in this course for the next year". To assess coping self-efficacy, a 7-item scale was used with a 9-point Likert scale that ranges from 0 (no confidence at all) to 9. Some of the questions were: "I feel confident to be able to continue my studies, even if I feel that the classroom environment was not welcoming".

To explore specific supports, a 5-item scale was used. These items were related to positive environmental cues that students received from friends, family, teachers as well as economic factors that facilitate their career. The response format was a 4-point Likert that ranges from 1 (No at all likely) to 5 (Extremely likely). Example items included: "During the first year, did you get financial support to continue your studies?" To identify barriers, a 6-item scale was used. This scale described obstacles that students receive during their career such as discrimination, lack of teacher support and issues with peers. The response format was in Likert format that ranges from 1 (No at all likely) to 5 (Extremely likely). Example items included: "During the first year, have you felt discouraged by the lack of social support?". This questionnaire was adapted using specific procedures to adapt psychological tests [32].The engineering field questionnaire has shown good psychometric properties and it has been used in engineering students $[21,33]$.

\subsection{Statistical analysis}

Since the study aim was to confirm and explore effects from supports and barriers in first-year students, we designed a Structural Equation Model (SEM) [34]. In addition to this, data were analyzed in SPSS $\subset$ IBM 23 and modelling was executed in AMOSC 21 [35].

\section{Results}

\subsection{Independent Variables}

Barriers and supports were tested as independent variables, individual scores were obtained through exploratory factor analysis (Table 1).
Table 1: Independents variables from barriers and support in first-year

\begin{tabular}{|c|c|c|c|}
\hline Factors & Independent variable & $\begin{array}{l}\text { Number of } \\
\text { categories }\end{array}$ & Estimate \\
\hline \multirow{4}{*}{$\begin{array}{c}\text { First-year } \\
\text { Support }\end{array}$} & $\begin{array}{l}\text { Social Acceptance } \\
\text { Support }\end{array}$ & \multirow{4}{*}{4} & 0.705 \\
\hline & Family Support & & 0.716 \\
\hline & Economic Support & & 0.632 \\
\hline & Teacher Support & & 0.620 \\
\hline \multirow{5}{*}{$\begin{array}{c}\text { First-year } \\
\text { Barriers }\end{array}$} & Social Barriers & \multirow{5}{*}{5} & 0.606 \\
\hline & Economic Barriers & & 0.420 \\
\hline & Teacher Barriers & & 0.367 \\
\hline & Gender Barriers & & 0.870 \\
\hline & Racial Barriers & & 0.843 \\
\hline
\end{tabular}

Estimate $>0.50$

\subsection{Confirmatory Factor Analysis}

A confirmatory factor analysis (CFA) was implemented in order to confirm correlation relationships between the three factors proposed (self-Efficacy, goals \& cope self-efficacy). A maximum likelihood (ML) estimation method was performed, providing acceptable model fit to the data: $\mathrm{X}^{2}=216.806 ; \mathrm{df}=83$; $\mathrm{p}<0.001 ; \mathrm{CFI}=0.963 ; \mathrm{TLI}=0.954$; RMSEA $[90 \% \mathrm{CI}]=0.062$ (0.052;0.072); SRMR $=0.059$.

As shown in Table 2, validity measures and the internal consistency were explored through Cronbach's alpha $(\alpha)$, Composite reliability (CR) and the Average Variance Extracted (AVE). These were confirmed in reliability and convergent validity measures.

Table 2: Cross-construct correlation and validity measures

\begin{tabular}{|c|c|c|c|c|c|c|}
\hline Factors & $\boldsymbol{\alpha}$ & $\mathbf{C R}$ & $\mathbf{A V E}$ & Goal & $\begin{array}{c}\text { Self- } \\
\text { Efficacy }\end{array}$ & $\begin{array}{c}\text { Cope Self- } \\
\text { Efficacy }\end{array}$ \\
\hline Goal & 0.800 & 0.834 & 0.568 & $\mathbf{0 . 7 5 4}$ & & \\
\hline $\begin{array}{c}\text { Self- } \\
\text { Efficacy }\end{array}$ & 0.878 & 0.866 & 0.624 & 0.406 & $\mathbf{0 . 7 9 0}$ & \\
\hline $\begin{array}{c}\text { Cope Self- } \\
\text { Efficacy }\end{array}$ & 0.896 & 0.887 & 0.531 & 0.365 & 0.540 & $\mathbf{0 . 7 2 8}$ \\
\hline
\end{tabular}

\subsection{The validity of the causal structure}

When CFA was confirmed, the path diagram modelled was tested in this phase. In order to determinate the predictive effects of barriers and supports on cognitive variables (self-efficacy, goals \& cope self-efficacy), a SEM analysis was conducted using ML estimation. The SEM estimation including ML produced the following goodness of fit indices: $\mathrm{X}^{2}=405,946$; $\mathrm{df}=193$; $\mathrm{p}<0.001 ; \mathrm{CFI}=0.957 ; \mathrm{TLI}=0.938 ; \operatorname{RMSEA}[90 \% \mathrm{CI}]=0.051$ $(0.044 ; 0.058) ; \mathrm{SRMR}=0.079$.

The results of path relationships confirmed the model proposed (Fig. 1), indicating a significant standardized regression coefficient and a positive relationship between family supports and self-Efficacy (SE), goals (GL) and cope self-efficacy (CSE), thus, confirming $\mathrm{H} 2 \mathrm{a}(\beta=0.192 ; \rho<0.05), \mathrm{H} 2 \mathrm{~b}(\beta=0.166 ; \rho<0.05)$, 
and $\mathrm{H} 2 \mathrm{c}(\beta=0.135 ; \rho<0.05)$; at the same time, a relationship between teacher support and CSE was identified, confirmed $\mathrm{H} 4 \mathrm{c}$ $(\beta=0.186 ; \rho<0.05)$.

Accordingly, negative effects were found on individual variables because barriers were perceived during first year; social barriers on SE \& CSE was established as a significant negative condition, confirming H5a $(\beta=-0.185 ; \rho<0.05)$ and $H 5$ c $(\beta=-$ $0.129 ; \rho<0.05)$. Also, teacher barriers had negative effects on SE $\&$ CSE, confirming H8a $(\beta=-0.161 ; \rho<0.05)$ and H8c $(\beta=-0.300$; $\rho<0.001$ ); while racial barriers had negative effects on Goals, confirming $\mathrm{H} 9 \mathrm{~b}(\beta=-0.212 ; \rho<0.05)$. In relation to economic barriers, although effects on CSE were identified as significant, the effects were not recognized as negative, thus, rejecting H6c $(\beta=0.11 ; \rho<0.05)$.

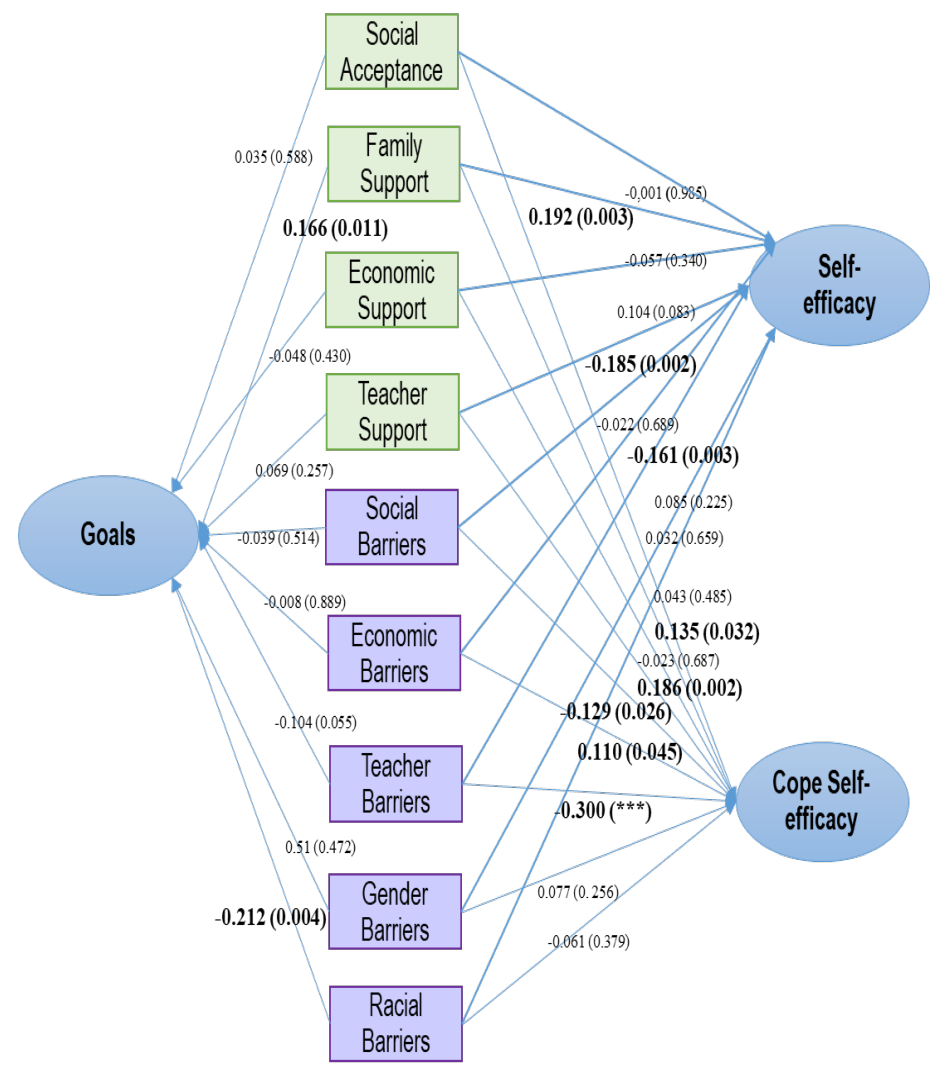

Figure 1: Path relationships confirmed the model proposed. *** $\mathrm{p}<0.001 ; * * \mathrm{p}<$ $0.01 ; * \mathrm{p}<0.05$

\section{Discussions and Conclusions}

The present research aimed to generate insights into contextual factors that may hinder or promote Peruvian engineering student's career progress during their first-year. The present study identified that family support was the major factor that contributes to self-efficacy, goals and cope self-efficacy. A possible explanation for this is that family support may represent acceptance among students because it guarantees economic support for other family members. This study confirms the findings from Peña-Calvo and colleagues [21], who found that family has a strong direct and indirect influence on SCCT factors in undergraduate engineering students. This finding reflects the importance of the effective role that family play in student's college life. For instance, parents may need to understand that students not only face academic challenges but also social and personal challenges (making friends, extracurricular activities, take own responsibility, time management, etc.). Future studies should assess and intervene family dynamics (e.g. authoritarian, permissive parenting style) and misconceptions that parents of first-year students may have about college life.

One interesting finding was the positive and negative effects of teacher's support on cope self-efficacy. This result may be explained by the fact that most of the students in our sample came from families who only had basic education and low income. In addition to this, Peruvian national state universities lack specialized online resources for engineering students, thus, making the role of teacher support critical for students coping and success. These conditions may limit students to find extra academic support and make the role of teachers critical to influence student's capacity to solve issues during their career. These results further support the idea that contextual factors among Peruvian students may influence the decision to continue or dropout higher education [4]. This finding also accords with earlier reports that identified that poor quality in teaching and advice influenced the decision to leave engineering careers [9]. These results have practical implications for Peruvian engineering faculties and teachers because first-year courses are challenging and there are high expectations of academic performance among students $[9,10]$. Teachers may have the potential to boost selfefficacy on students by providing adequate supports such as positively interpreting their failures, reduce career biases and minimize possible withdrawal.

Another interesting finding was the effect of social barriers (e.g. family, friends) on self-efficacy and coping self-efficacy. It seems possible that negative comments, a sense of not belonging to that particular group and family pressure may diminished students repertoire to cope with adverse situations as well as their judgment on their own capabilities. This result was also reported by Peña-Calvo and colleagues [21] who concluded that peer barriers is a predictor of self-efficacy and goals, which may be determinant for students career development. This finding further support the idea of Wilcox and colleagues [25] who showed the importance of family and friends support in first-year students. This finding highlights implications for student's social relationships and family dynamics. With intention or due to a lack of knowledge, family members and students may negatively influence in the decision to continue engineering degree. As a result, this situation may increase engineering career gaps in Peruvian engineering faculties. Therefore, strategies to enhance positive student's relationships and provide training to families on how to support first-year students may be beneficial.

In this study, racial discrimination had effects on goals. One possible explanation is that racial discrimination may be perceived as a long-term issue and this may affect student's determination to continue engineering career. Another possible explanation is the lack of policies related to race/ethnicity discrimination in student's universities. This finding is consistent with previous studies that found that racial discrimination influence student's decisions to leave engineering career $[14,36$, 37]. Further research should be undertaken to investigate other 
types of aversive interactions among students such as bullying, sexual orientation and sexual harassment.

The aim of the present research was to examine specific barriers and supports and possible effects on self-efficacy, copingself efficacy and goals among first-year Peruvian engineering college students. This study may lay the foundation for further exploration in college dropouts, teacher support, racial discrimination and the role of peers in continuing engineering careers. For instance, further studies may explore these issues using qualitative research or longitudinal designs.

A limitation of this study is the low number of women, which may biased results. However, this gender proportion was aligned with national statistics reports [4]. The major limitation of this study is the low number of items to explore specific barriers and supports. Despite its exploratory nature, this study offers some insights into environmental factors that influence engineering career development in the Peruvian context. Further research might explore these weaknesses by using robust psychometric questionnaires and/or conducting multi-group analyses. These findings suggest several courses of action at many levels in Peruvian universities with engineering careers. For instance, policies that systematically assess these specific barriers and supports among students may be helpful to promote engineering persistence in first-year students. In addition to this, economic incentives from government agencies to universities who minimize these barriers (e.g. by creating students unions) may be useful and beneficial to students and society as a whole. In addition to this, training psychologists and tutors with SCCT framework may boost the quality of staff and student's relationships.

\section{Conflict of Interest}

The authors declare no conflict of interest.

\section{Acknowledgment}

We acknowledge the support of the Project 104-2017FONDECYT funded by Consejo Nacional de Ciencia, Tecnología e Innovación Tecnológica - CONCYTEC and Consorcio de Investigación Económica y Social - CIES.

\section{References}

[1] R. Atkinson, M. Mayo, Refueling the U . S . Innovation Economy : Fresh Approaches to Science, Technology, Engineering and Mathematics (STEM) Education, 2010

[2] R.D. Atkinson, How ICT Can Restore Lagging European Productivity Growth, 2018.

[3] A. Fiszbein, C. Cosentino, B. Cumsille, El desafio del desarrollo de habilidades en América Latina: Un diagnóstico de los problemas y soluciones de política pública, Washington, DC, 2016.

[4] Superintendencia Nacional de Educación Superior Universitaria SUNEDU, II Informe Bienal sobre la realidad universitaria en el Perú, 2020.

[5] Asamblea Nacional de Rectores, Datos Estadísticos Universitarios, Lima, 2011.

[6] R.W. Lent, M.J. Miller, P.E. Smith, B.A. Watford, K. Hui, R.H. Lim, "Social cognitive model of adjustment to engineering majors: Longitudinal test across gender and race/ethnicity," Journal of Vocational Behavior, 83(1), 22-30, 2013, doi:10.1016/j.jvb.2014.11.004.

[7] K.E. Snyder, S.M. Barr, N.B. Honken, C.M. Pittard, P.A.S. Ralston, "Navigating the First Semester: An Exploration of Short-Term Changes in Motivational Beliefs Among Engineering Undergraduates," Journal of Engineering Education, 107(1), 11-29, 2018, doi:10.1002/jee.20187.
[8] E. Godfrey, T. Aubrey, R. King, "Who leaves and who stays? Retention and attrition in engineering education," Engineering Education 2010: Inspiring the Next Generation of Engineers, EE 2010, 0052, 2010, doi:10.11120/ened.2010.05020026.

[9] R.M. Marra, K.A. Rodgers, D. Shen, B. Bogue, "Leaving engineering: A multi-year single institution study," Journal of Engineering Education, 101(1), 6-27, 2012, doi:10.1002/j.2168-9830.2012.tb00039.x.

[10] B.N. Geisinger, D.R. Raman, "Why they leave: Understanding student attrition from engineering majors," International Journal of Engineering Education, 29(4), 914-925, 2013.

[11] R.W. Lent, S.D. Brown, G. Hacket, "Toward Unifying Social Cognitive THoery of Career and Academic Interest, Choice, and Performance," Journal of Vocational Behavior, 45, 79-122, 1994.

[12] R.W. Lent, S. Brown, G. Hackett, "Contextual supports and barriers to career choice: A social cognitive analysis," Journal of Counseling Psychology, 47(1), 36-49, 2000, doi:http://dx.doi.org/10.1037/0022-0167.47.1.36.

[13] R.W. Lent, T.R. Morris, L.T. Penn, G.W. Ireland, "Social-cognitive predictors of career exploration and decision-making: Longitudinal test of the career self-management model," Journal of Counseling Psychology, 66(2), 184-194, 2019, doi:10.1037/cou0000307.

[14] R.W. Lent, H. Bin Sheu, M.J. Miller, M.E. Cusick, L.T. Penn, N.N. Truong, "Predictors of science, technology, engineering, and mathematics choice options: A meta-analytic path analysis of the social-cognitive choice model by gender and race/ethnicity," Journal of Counseling Psychology, 65(1), 1735, 2018, doi:10.1037/cou0000243.

[15] A. Bandura, "Self-Efficacy Mechanism in Human Agency," American Psychologist, 37(2), 122-147, 1982.

[16] A. Bandura, "Perspectives on Psychological Science Toward a Psychology of Human Agency," 2013, doi:10.1111/j.1745-6916.2006.00011.x.

[17] R.W. Lent, S.D. Brown, "On Conceptualizing and Assessing Social Cognitive Constructs in Career Research : A Measurement Guide," 14(1), 12-35, 2006, doi:10.1177/1069072705281364.

[18] R.W. Lent, S.D. Brown, J. Schmidt, B. Brenner, H. Lyons, D. Treistman, "Relation of contextual supports and barriers to choice behavior in engineering majors: Test of alternative social cognitive models.," Journal of Counseling Psychology, 50(4), 458-465, 2003, doi:10.1037/00220167.50.4.458

[19] I. Fort, A. Murariu, "The Paths Between Gender, Barriers, Social Support, Coping Efficacy, and Educational Goals," Journal of Career Assessment, 26(1), 68-76, 2018, doi:10.1177/1069072716679924.

[20] M.F. Shoffner, D. Newsome, C.A. Barrio Minton, C.A. Wachter Morris, “A qualitative exploration of the STEM career-related outcome expectations of young adolescents," Journal of Career Development, 42(2), 102-116, 2015.

[21] J. Peña-Calvo, M. Inda-caro, C. Rodriguez-Menèndez, C. Fernandez-Garìa, "Perceived supports and barriers for career development for second-year STEM students," Journal of Engineering Education, 105(2), 2016, doi: $10.1002 /$ jee. 20115

[22] J.J. Dahling, M.N. Thompson, "Contextual supports and barriers to academic choices: A policy-capturing analysis," Journal of Vocational Behavior, 77(3), 374-382, 2010, doi:10.1016/j.jvb.2010.07.007.

[23] N.A. Fouad, G. Hackett, P.L. Smith, N. Kantamneni, M. Fitzpatrick, S. Haag, D. Spencer, "Barriers and Supports for Continuing in Mathematics and Science: Gender and Educational Level Differences," Journal of Vocational Behavior, 77(3), 361-373, 2010, doi:10.1016/j.jvb.2010.06.004.

[24] M.C. Cadaret, P.J. Hartung, L.M. Subich, I.K. Weigold, "Stereotype threat as a barrier to women entering engineering careers," Journal of Vocational Behavior, 99, 40-51, 2017, doi:10.1016/j.jvb.2016.12.002.

[25] P. Wilcox, S. Winn, M. Fyvie-Gauld, "It was nothing to do with the university, it was just the people': The role of social support in the first-year experience of higher education," Studies in Higher Education, 30(6), 707722, 2005, doi:10.1080/03075070500340036.

[26] K.A. Tate, W. Caperton, D. Kaiser, N.T. Pruitt, H. White, E. Hall, “An Exploration of First-Generation College Students' Career Development Beliefs and Experiences," Journal of Career Development, 42(4), 294-310, 2015, doi:10.1177/0894845314565025.

[27] M.E. Kenny, D.L. Blustein, A. Chaves, J.M. Grossman, L.A. Gallagher, "The role of perceived barriers and relational support in the educational and vocational lives of urban high school students," Journal of Counseling Psychology, 50(2), 142, 2003.

[28] R.W. Lent, S.D. Brown, B. Brenner, S.B. Chopra, T. Davis, R. Talleyrand, V. Suthakaran, "The Role of Contextual Supports and Barriers in the Choice of Math / Science Educational Options: A Test of Social Cognitive Hypotheses," Journal of Counseling Psychology, 48(4), 474-483, 2001, doi:10.1037//0022-0167.48.4.474.

[29] M. Inda, C. Rodríguez, J.V. Peña, "Gender differences in applying social 
cognitive career theory in engineering students," Journal of Vocational Behavior, 83(3), 346-355, 2013, doi:10.1016/j.jvb.2013.06.010.

[30] Superintendencia Nacional de Educación Superior Universitaria SUNEDU, Informe Bienal sobre la realidad universitaria en el Perú, 2018.

[31] M. Rodriguez-Menendez, M. Inda-Caro, J. Peña-Calvo, "Validacion de la teorìa cognitivo social de desarrollo de la carrera con una muestra de estudiantes de ingenierìa.," Educacion 18(2), 257-276, 2015, doi:10.5944/educXX1.14018.

[32] J. Muñiz, P. Elosua, R.K. Hambleton, "Directrices para la traducción y adaptación de los tests: segunda edición [Guidelines for the translation and adaptation of test: ]," Psicothema, 25(2), 151-157, 2013.

[33] M. Inda-Caro, C. Rodríguez-Menéndez, J.V. Peña-Calvo, "Spanish High School Students' Interests in Technology: Applying Social Cognitive Career Theory," Journal of Career Development, 43(4), 291-307, 2016, doi:10.1177/0894845315599253.

[34] J.F. Hair, W.C. Black, B.J. Babin, R.E. Anderson, R.L. Tatham, Multivariate data analysis, Prentice hall Upper Saddle River, NJ, 1998.

[35] B. Byrne, Structural equation modeling with AMOS: basic concepts, applications, and programming, 2010, doi:10.4324/9781410600219.

[36] L.Y. Flores, R.L. Navarro, S.R. Ali, "The State of SCCT Research in Relation to Social Class: Future Directions," Journal of Career Assessment, 25(1), 6-23, 2017, doi:10.1177/1069072716658649.

[37] R.L. Navarro, L.Y. Flores, H.S. Lee, R. Gonzalez, "Testing a longitudinal social cognitive model of intended persistence with engineering students across gender and race/ethnicity," Journal of Vocational Behavior, 85(1), 146-155, 2014, doi:10.1016/j.jvb.2014.05.007. 